\title{
Editorials
}

\section{Scientific publishing, transparency and the role of the medical library}

All scientific journals are nowadays available in electronic format. Some journals are available only in electronic format. MEDLINE now lists more than 5000 biomedical journals from more than 80 countries worldwide. SciFinder Scholar includes all MEDLINE listings, and adds another 1000 chemical journals. SciFinder Scholar also has a number of features that are incredibly valuable and advanced - for example finding the two- or even three-dimensional structure of a chemical compound is easily done in this database. Google Scholar and Scope are other examples to be added to the list of databases available for search from home or through medical libraries. Lindberg and Humphreys ${ }^{1}$ envisage the future medical library as a commodity responding to the everincreasing need for more high-quality electronic information, delivered as a package, including different relevant consensus statements and/or protocols for easyand-quick access. The demands in the future will possibly also include instructional videos, high-resolution graphics, and freedom from any commercial offers. Mastering all these electronic resources is, and will increasingly be, of immense importance in the advancement of research frontiers. The medical librarians of today obviously see their role as previously, as suppliers of information as well as of space for studies and meetings. According to the Code of Ethics of the European Association for Health Information and Libraries ${ }^{2}$, they also see themselves as having an educational role and being a resource centre for information technology and web development. Librarians' role in providing an ethical framework for publications and as beacons of transparency when it comes to authorship and sponsorship has been progressively important over the years.

\section{MEDLINE barring non-transparent supplements}

Very soon, MEDLINE introduces a barring of journal supplements which do not include disclosure statements regarding commercial funding or even funding from nonprofit organisations $s^{3-5}$. This strengthened disclosure policy for supplements was partly due to an intervention by the Center for Science in the Public Interest (CSPI) ${ }^{6}$, questioning a recent supplement in the Journal of the American College of Nutrition regarding salt intake, edited by an advisor to the International Life Sciences Institute (ILSI) and seen by CSPI as downplaying the health risks of salt intake. ILSI ${ }^{8}$ is known within the United Nations system as a BINGO - business interest NGO. It has charitable status and many independent scientific advisors, but its governing body and most if not all of its core funding is from industry, including many leading manufacturers whose products are formulated with large amounts of salt. In the larger scope of the medical library, this type of sponsored supplements normally invoives pharmaceutical companies. The example above and many others ${ }^{9}$, however, points at the need for transparency when it comes to food-related publications as well. Out of the 2005 journal issues, around 4\% (growing number) were funded by drug companies but did not disclose that the companies had paid some authors to write articles about their products ${ }^{4}$. We have obviously seen the need for transparency when it comes to food-related publications as well, as in the example above and in our recent editorial ${ }^{9}$. The editorial in Lancet $^{5}$ even suggests more rigorous indexing rules for MEDLINE - and asks "Why tarnish MEDLINE's reputation by publishing these types of supplements at all? And considering those users with restricted skills whose sole access is to MEDLINE abstracts, this is certainly a question we should ask ourselves. Maybe disclosure statements should be included in all abstracts in order to provide the optimal amount of information and transparency? This journal's policy is to have all papers peer-reviewed, in regular issues as well as supplements. Furthermore, in the new author guidelines, we are discussing inclusion of disclosure of funding and conflicts of interest in all abstracts, in order to further enlighten information seekers with access solely to abstracts. Maybe the National Library of Medicine ${ }^{3}$ will beat us to it.

\section{Agneta Yngve}

Editor-in-Chief

Email: agneta.yngve@prevnut.ki.se

\section{References}

1 Lindberg DA, Humphreys BL. 2015 - the future of medical libraries. New England Journal of Medicine 2005; 352(11): 1067-70.

2 European Association for Health Information and Libraries. Code of ethics for EAHIL members [online]. Available at http:// www.eahil.net/code_ethics.htm. Accessed 2 January 2007.

3 US National Library of Medicine. Fact Sheet: Response to Inquiries about Journal Selection for Indexing [online]. 
Available at http://www.nlm.nih.gov/pubs/factsheets/ j_sel_faq.html. Accessed 4 January 2007.

4 Kaiser J. Scientific publishing. MEDLINE supplements must list corporate ties. Science 2006; 314(5798): 405.

5 Anon. Read MEDLINE abstracts with a pinch of salt. Lancet 2006; 368(9545): 1394.

6 Center for Science in the Public Interest. Integrity in Science Watch Week of 10/02/2006: Nutrition Journal Failed to Disclose Editor's and Authors' Ties to Salt Industry [online].
Available at http://cspinet.org/integrity/watch/200610021. html. Accessed 4 January 2007.

7 Logan AG. Dietary sodium intake and its relation to human health: a summary of the evidence. Journal of the American College of Nutrition 2006; 25(3 Suppl.): 5 p preceding 231 S.

8 International Life Sciences Institute. Homepage: www.ilsi.org.

9 Margetts B. Stopping the rot in nutrition science [Editorial]. Public Health Nutrition 2006; 9(2): 169-73.

\section{Fruit and vegetables revisited}

This issue of Public Health Nutrition continues in its tradition of offering a broad range of topics, ranging from social-contextual influences on food habits ${ }^{1}$ to the association between dietary intake and health-related biomarkers $^{2}$ or outcomes ${ }^{3}$ to methodological problems in assessment of dietary intake ${ }^{4-5}$. A common theme of several of the papers published in this issue, however, is fruit and vegetable intake.

Among cohorts of 9-10-year old children surveyed throughout Liverpool, Johnson and Hackett found increases in fruit, vegetable and salad intakes over the five-year period between 2000 and $2005^{6}$. Although the proportions of children reporting vegetable and salad consumption were generally low, the upward trends are still promising. Factors contributing to these positive trends remain unclear, but also in this issue Baranowski et al. offer their work on scales to assess parents' outcome expectancies for purchasing fruits and vegetables ${ }^{7}$. Their research is a step towards clarifying the factors that motivate parents to have fruits and vegetables available in the home, with natural implications for their children's habitual intake of these foods. Whether and how schools might also have a positive impact on children's fruit and vegetable intake is addressed in an article by Mangunkusumo et $\mathrm{al}^{8}$. They found that an Internet-based, tailored feedback and counselling intervention improved knowledge and awareness of fruit and vegetable intake to some extent, but not actual intake, suggesting that other, more comprehensive approaches would be needed in a school setting.

In examining determinants of fruit and vegetable intake among adults, Crawford et al. examined a unique set of behaviours in a sample of women and discovered that forward-planning and enjoyment of the meal process were associated with higher fruit and vegetable intake, while food-related behaviours indicating less time and thought set aside for meals were associated with lower intake?
Fruit and vegetable intake in their sample was low overall, consistent with other samples, and many of the behaviours associated with high intake of these foods were not widely practised. Nevertheless, their findings suggest some strategies for encouraging their intake, beginning with an attitudinal shift towards developing a good relationship with one's meals.

Lassen et al. examined à la carte versus buffet-style cafeterias at worksites and found that eating at buffet-style cafeterias was associated with greater intake of fruits and vegetables and with lower energy density of the food ${ }^{10}$. Eating buffet style was also associated with consumption of a larger portion size compared with eating à la carte, but only among women. Further, because of lower energy density associated with eating in buffet-style cafeterias, energy intake was similar between the two meal serving systems. Their findings are surprising given the potential for overeating that buffets seem to offer, and they provide reason for optimism that people do choose the right foods when given the choice. Whether this has implications for eat-out food behaviours in general remains to be seen.

Overall, these articles provide a picture of where we are in our knowledge of the status of fruit and vegetable intake in public health nutrition. It is on the rise, at least in some samples, and when fruits and vegetables are available (and presumably, presented as an attractive option), people will choose to eat them. The bad news, of course, is that consumption remains generally quite low. So the question remains: how to encourage people of all ages to eat more of them? The authors in this issue suggest a variety of possible strategies to pursue, including increasing availability at home and in cafeterias, and altering attitudes and behaviours towards the meal process, from food shopping to meal preparation to the meal itself. Ultimately, we are working towards the goal of viewing fruits and vegetables as crucial and primary components of our diets, 
rather than as food items that must be eaten in order to meet a five-a-day quota.

\section{Marilyn Tseng}

Editor

Email: M_Tseng@fccc.edu

\section{References}

1 Roos E, Sarlio-Lähteenkorva S, Lalluka T, Lahelma E. Associations of work-family conflicts with food habits and physical activity. Public Health Nutrition 2007; 10(3): 222-229.

2 Bermejo LM, Aparicio A, Andrés P, López-Sobaler AM, Ortega RM. The influence of fruit and vegetable intake on the nutritional status and plasma homocysteine levels of institutionalised elderly people. Public Health Nutrition 2007; 10(3): 266-272.

3 Randi G, Pelucchi C, Gallus S, Parpinel M, Dal Maso L, Talamini R, et al. Lipid, protein and carbohydrate intake in relation to body mass index: an Italian study. Public Health Nutrition 2007; 10(3): 306-310.

4 Rasmussen LB, Matthiessen J, Biltoft-Jensen A, Tetens I. Characteristics of misreporters of dietary intake and physical activity. Public Health Nutrition 2007; 10(3): 230-237.
5 Schlundt DG, Buchowski MS, Hargreaves MK, Hankin JH, Signorello LB, Blot WJ. Separate estimates of portion size were not essential for energy and nutrient estimation: results from the Southern Community Cohort food-frequency questionnaire pilot study. Public Health Nutrition 2007; 10(3): $245-251$

6 Johnson B, Hackett AF. Trends in fruit, vegetable and salad intakes in 9-10-year-old schoolchildren living in Liverpool, 2000-2005. Public Health Nutrition 2007; 10(3): $252-255$.

7 Baranowski T, Watson K, Missaghian M, Broadfoot A, Baranowski J, Cullen K, et al. Parent outcome expectancies for purchasing fruit and vegetables: a validation. Public Health Nutrition 2007; 10(3): 280-291.

8 Mangunkusumo RT, Brug J, de Koning HJ, van der Lei J, Raat H. School-based Internet-tailored fruit and vegetable education combined with brief counselling increases children's awareness of intake levels. Public Health Nutrition 2007; 10(3): 273-279.

9 Crawford D, Ball K, Mishra G, Salmon J, Timperio A. Which food-related behaviours are associated with healthier intakes of fruits and vegetables among women? Public Health Nutrition 2007; 10(3): 256-265.

10 Lassen A, Hansen KS, Trolle E. Comparison of buffet and à la carte serving at worksite canteens on nutrient intake and fruit and vegetable consumption. Public Health Nutrition 2007; 10(3): 292-297. 